\title{
Morphological characteristics of Potentilla fruticosa in the urban ecosystem of Novosibirsk city
}

\author{
Anna Lugovskaya ${ }^{{ }^{*}}$ \\ ${ }^{1}$ Siberian State University of Geosystems and Technologies, ul. Plakhotnogo 10, Novosibirsk 630108, \\ Russia
}

\begin{abstract}
Changes in leaf morphological characteristics in Potentilla fruticosa growing under the transport and industrial pollution conditions in the city of Novosibirsk have been studied. Leaf morphological characteristics were determined by computer image analysis using geographical information systems (GIS). It was found that, in response to anthropogenic disturbance, the size of the assimilating organs of plants decreased by a factor of $1.2-4.5$ and the leaf fluctuating asymmetry increased compared to these parameters in control plants; the urban area had a high level of environmental pollution, and the control area a low level.
\end{abstract}

In recent years, the environmental conditions of Novosibirsk, a major industrial city in Russia, have remained stressful. Moreover, there is a tendency for their deterioration, mainly due to an increase in the number of vehicles, anthropogenic soil pollution, and other factors [1]. Shrubby cinquefoil (Potentilla fruticosa L. = Dasiphora fruticosa (L.) Rydb. = Pentaphylloides fruticosa (L.) O. Schwarz) is a beautiful flowering wild shrub, which attracts attention with its decorativeness, has bioindicator properties, and is used in amenity planting in Novosibirsk.

The objectives of this study were to determine the morphometric parameters of the leaf blade in Potentilla fruticosa, identify their changes under the impact of transport and industrial pollution in Novosibirsk, and establish the most prominent criterion for environmental assessment.

One of the most environmentally adverse anthropogenic factors in Novosibirsk is air pollution by emissions from motor vehicles and industrial facilities. In Novosibirsk, the main pollutants present in air at concentrations above the maximum permissible concentrations (MPCs) are suspended solids (dust), nitrogen oxides, ammonia, carbon monoxide, formaldehyde, and 3,4-benzo(a)pyrene [1-5]. Depending on the city district, the environmental situation changes significantly — from slight pollution in the Sovetskii and Pervomaiskii districts to severe pollution in the Leninskii, Kirovskii, Tsentral'nyi, and Oktyabr'skii districts.

\footnotetext{
* Corresponding author: aulyg@mail.ru
} 
The effect of transport and industrial pollution on morphological parameters was studied on $P$. fruticosa shrubs growing on lawns along highways in three districts of the city (Zheleznodorozhnyi, Leninskii, and Sovetskii) with different pollutant compositions and concentrations over a four-year period, from 2012 to 2015. The control plants were plants growing at the introduction site of the Central Siberian Botanical Garden, SB RAS located in the environmentally most favorable Sovetskii district (Fig. 1)

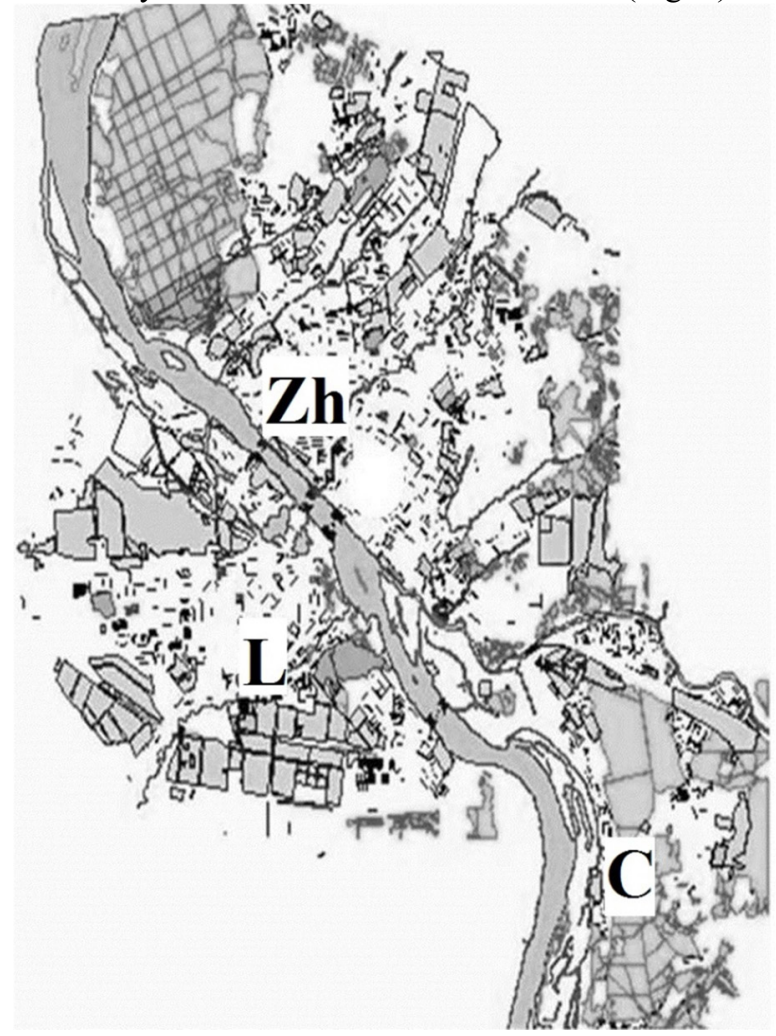

Fig. 1. Map of sampling locations of Potentilla fruticosa planted in Novosibirsk: L - Leninskii district, Zh - Zheleznodorozhnyi district, C - Sovetskii district (control).

Morphological studies were carried out at the time of mass flowering in 2012-2015. Ten annual shoots were collected from each plant and pooled to form an average sample. All specimens of each sample were placed in plastic bags marked with species, variety, and sampling location and date.

Leaf morphometric parameters (area, perimeter, length, and width of the leaf blade and terminal lobe, and leaf-stalk length) were measured by computer image analysis using MapInfo Professional Geographical Information System (GIS) software [3-5]. The fluctuating asymmetry (FA) was calculated by the generally accepted formula using the normalized difference algorithm [2,6-13]. The quality of the urban environment was determined according to the Kuznetsov-Golyshkin sustainable development scale [14]

Microsoft Excel and Statistica programs were used for statistical analysis. The significance of the results was evaluated using the non-parametric Mann-Whitney test (U) at a significance level $\mathrm{p} \leq 0.05$.

The study in the period from 2012 to 2015 showed that transport and industrial pollution caused a statistically significant decrease in the area, length, and width of the leaf blade and terminal lobe, and leaf-stalk length in plants from urban areas compared to those from the control area, regardless of the year of observation (Table 1). 
Table 1. Morphological characteristics of Potentilla fruticosa plants growing in urban and control areas.

\begin{tabular}{|c|c|c|c|c|c|c|c|c|c|c|}
\hline 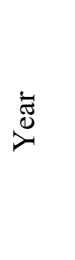 & 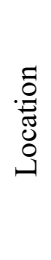 & 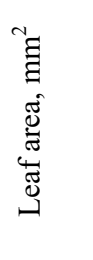 & 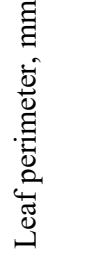 & 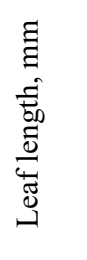 & 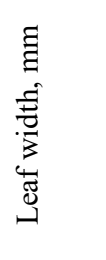 & 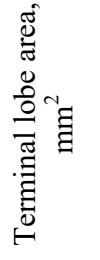 & 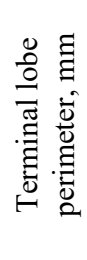 & 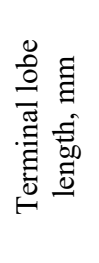 & 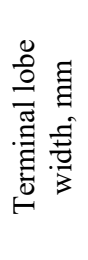 & 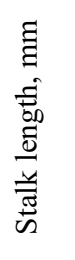 \\
\hline \multirow[t]{3}{*}{2012} & $\mathrm{~L}^{1}$ & $\begin{array}{l}212 \pm 1 \\
63^{2}\end{array}$ & $\begin{array}{l}119 \pm 5 \\
7^{*}\end{array}$ & $21 \pm 8$ & $27 \pm 7^{*}$ & $42 \pm 7$ & $24 \pm 7$ & $11 \pm 5^{2}$ & $5 \pm 3$ & $7 \pm 4$ \\
\hline & $\mathrm{Zh}$ & $\begin{array}{l}199 \pm 1 \\
57^{*}\end{array}$ & $\begin{array}{l}137 \pm 4 \\
1^{*}\end{array}$ & $23 \pm 7$ & $\begin{array}{ll}29 & \pm \\
6^{*} & \end{array}$ & ${ }_{*}^{46 \pm 15}$ & $26 \pm 6$ & $13 \pm 4$ & $6 \pm 5$ & $9 \pm 6$ \\
\hline & $\mathrm{C}$ & $\begin{array}{l}502 \pm 2 \\
7\end{array}$ & $\begin{array}{l}261 \pm 2 \\
9\end{array}$ & $35 \pm 3$ & $38 \pm 2$ & $81 \pm 2$ & $31 \pm 1$ & $19 \pm 2$ & $9 \pm 1$ & $11 \pm 2$ \\
\hline \multirow[t]{3}{*}{2013} & $\mathrm{~L}$ & $\begin{array}{l}289 \pm 1 \\
19^{*}\end{array}$ & $\begin{array}{l}121 \pm 5 \\
9^{*}\end{array}$ & $20 \pm 7$ & $23 \pm 6^{*}$ & $37 \pm 29$ & $21 \pm 8$ & $9 \pm 5^{*}$ & $5 \pm 2$ & $6 \pm 6^{*}$ \\
\hline & $\mathrm{Zh}$ & $\begin{array}{l}301 \pm 8 \\
7^{*}\end{array}$ & $\begin{array}{l}137 \pm 4 \\
7^{*}\end{array}$ & $29 \pm 5$ & $24 \pm 7^{*}$ & $\underset{*}{52 \pm 16}$ & $24 \pm 7$ & ${ }_{*}^{12 \pm 23}$ & $7 \pm 2^{*}$ & $8 \pm 4$ \\
\hline & $\mathrm{C}$ & $\begin{array}{l}702 \pm 1 \\
79\end{array}$ & $\begin{array}{l}394 \pm 1 \\
1\end{array}$ & $37 \pm 2$ & $35 \pm 2$ & $93 \pm 11$ & $41 \pm 2$ & $22 \pm 2$ & $11 \pm 1$ & $13 \pm 3$ \\
\hline \multirow[t]{3}{*}{2014} & $\mathrm{~L}$ & $\begin{array}{l}211 \pm 9 \\
8^{*}\end{array}$ & $\begin{array}{l}119 \pm 1 \\
7^{*}\end{array}$ & $21 \pm 5$ & $24 \pm 3^{*}$ & $\begin{array}{l}42 \pm 11 \\
*\end{array}$ & $23 \pm 5$ & $9 \pm 4^{*}$ & $4 \pm 1^{*}$ & $7 \pm 1^{*}$ \\
\hline & $\mathrm{Zh}$ & $\begin{array}{l}253 \pm 6 \\
7^{*}\end{array}$ & $\begin{array}{l}121 \pm 2 \\
7^{*}\end{array}$ & $31 \pm 5$ & $27 \pm 6^{*}$ & $68 \pm 11$ & $31 \pm 8$ & $14 \pm 1^{*}$ & $9 \pm 2^{*}$ & $10 \pm 1$ \\
\hline & $\mathrm{C}$ & $\begin{array}{l}613 \pm 7 \\
8\end{array}$ & $\begin{array}{l}314 \pm 4 \\
3\end{array}$ & $\begin{array}{l}41 \pm 1 \\
1\end{array}$ & $38 \pm 5$ & $\begin{array}{l}103 \pm 3 \\
1\end{array}$ & $\begin{array}{l}67 \pm 1 \\
2 \\
\end{array}$ & $25 \pm 4$ & $16 \pm 1$ & $13 \pm 2$ \\
\hline \multirow[t]{3}{*}{2015} & $\mathrm{~L}$ & $\begin{array}{l}116 \pm 5 \\
3^{*},\end{array}$ & $\begin{array}{l}46 \pm 21 \\
*\end{array}$ & $19 \pm 7$ & $18 \pm 5^{*}$ & $78 \pm 1$ & $41 \pm 8$ & $16 \pm 4$ & $10 \pm 2^{*}$ & $9 \pm 1$ \\
\hline & $\mathrm{Zh}$ & ${ }_{*}^{88 \pm 61}$ & ${ }_{*}^{47 \pm 33}$ & ${ }_{*} 13 \pm 4$ & $19 \pm 6^{*}$ & $80 \pm 17$ & $43 \pm 6$ & $16 \pm 3$ & $9 \pm 4$ & $9 \pm 2$ \\
\hline & $\mathrm{C}$ & $\begin{array}{l}437 \pm 1 \\
11\end{array}$ & $\begin{array}{l}209 \pm 5 \\
2\end{array}$ & $40 \pm 7$ & $41 \pm 5$ & $87 \pm 22$ & $49 \pm 7$ & $17 \pm 4$ & $14 \pm 2$ & $11 \pm 3$ \\
\hline
\end{tabular}

Note. ${ }^{1}$ - designation as in Fig. $1.1 ;^{2}$ - mean \pm standard deviation; ${ }^{*}$ - statistically significant differences between samples from urban and control areas at $p \leq 0.05$.

Based on the analysis of the morphometric parameters of $P$. fruticosa plants, the largest differences from the control were observed in plants growing in the Leninskii district. The area and perimeter of the leaf and its terminal lobe were 1.2-4.5 smaller and the length and width of the leaf and terminal lobe were 1.1-4 times smaller than those in control plants. In samples from the Zheleznodorozhnyi district, these parameters were $15-54 \%$ lower. The ratio of the leaf area of $P$. fruticosa from urban environments to the control increased over four years from 2.4 to 3.8 in the Leninskii district and from 2.2 to 4.9 in the Zheleznodorozhnyi district. The ratio of leaf perimeter in plants from urban environments to that in control plants also increased; it was $2-4.5$ in the Leninskii district and 1.7-4.4 in the Zheleznodorozhnyi district. A similar trend was observed for leaf length and width, which may indicate a deterioration of the environmental situation at the sampling points in these areas.

The impact of external factors, especially anthropogenic factors, leads to a distortion of the symmetry of the leaf blade. The FA of the terminal lobe of P. fruticosa leaf samples from urban areas was found to be 0.159 to 0.196 , which corresponds to the critical level of pollution, while in the control, it was only 0.04 , which is regarded as safe environmental 
conditions. The FA of the terminal leaf lobe in urban environments was 4-5 times higher than that in the control area (Table 2).

Table 2. Environmental quality at sampling points with different levels of anthropogenic pollution based on the value of fluctuating asymmetry of the terminal leaf lobe in Potentilla fruticose.

\begin{tabular}{|l|c|c|c|c|}
\hline Year & Location & FA & Score & Environmental quality \\
\hline \multirow{3}{*}{2012} & $\mathrm{~L}$ & $0.182 \pm 0.032^{1}$ & 5 & Critical pollution \\
\cline { 2 - 5 } & Zh & $0.159 \pm 0.023$ & 5 & High pollution \\
\cline { 2 - 5 } & $\mathrm{C}$ & $0.049 \pm 0.012$ & 1 & Norm \\
\hline \multirow{3}{*}{2013} & $\mathrm{~L}$ & $0.189 \pm 0.029$ & 5 & Critical pollution \\
\cline { 2 - 5 } & $\mathrm{Zh}$ & $0.169 \pm 0.019$ & 5 & Critical pollution \\
\cline { 2 - 5 } & $\mathrm{C}$ & $0.041 \pm 0.011$ & 1 & Norm \\
\hline \multirow{3}{*}{2014} & $\mathrm{~L}$ & $0.195 \pm 0.044$ & 5 & Critical pollution \\
\cline { 2 - 5 } & Zh & $0.177 \pm 0.041$ & 5 & Critical pollution \\
\cline { 2 - 5 } & $\mathrm{C}$ & $0.041 \pm 0.09$ & 1 & Norm \\
\hline \multirow{3}{*}{2015} & $\mathrm{~L}$ & $0.196 \pm 0.037$ & 5 & Critical pollution \\
\cline { 2 - 5 } & $\mathrm{Zh}$ & $0.178 \pm 0.03$ & 5 & Critical pollution \\
\cline { 2 - 5 } & $\mathrm{C}$ & $0.046 \pm 0.08$ & 1 & Norm \\
\hline
\end{tabular}

Note. ${ }^{\perp}-$ mean \pm standard deviation

The FA of the terminal lobe of the P. fruticosa leaf from the Leninskii district was $0.182-0.196$, which corresponds to a score of 5 points or the critical level of pollution, and in the Zheleznodorozhnyi district, this indicator was $11 \%$ lower, which corresponds to $4-5$ points (high pollution). In the control, the FA was $0.041-0.04$, which is estimated at 1 point and is the norm. Analysis of the FA of the terminal leaf lobe in P. fruticosa for four years shows a tendency for environmental conditions to deteriorate at all sampling points. At the same time, in the environmentally favorable Sovetskii district, considered as the control area, the FA coefficient did not practically change during the study period.

It is found that transport and industrial pollution led to a decrease in leaf-blade area and leaf-stalk length in P. fruticosa and an increase in the FA of the terminal leaf lobe. In the $P$. fruticosa leaf from urban environments subject to anthropogenic disturbance, the FA of the terminal lobe ranges from 0.159 to 0.196 , which corresponds to a critical state of the environment, whereas in the control, the FA value is 0.046 and corresponds to a favorable state. The districts can be ranked in increasing order of the FA of the terminal leaf lobe as follows: Sovetskii $<$ Zheleznodorozhnyi $<$ Leninskii, which is consistent with the data on air pollution in Novosibirsk from the West Siberian AHEM.

\section{Conclusions}

Transport and industrial pollution leads to a reduction in leaf-blade area in $P$. fruticosa, a decrease in leaf-stalk length, and an increase in the FA of the terminal leaf lobe. By increasing the FA value, the regions can be ranked as follows: Sovetskii < Zheleznodorozhnyi < Leninskii. The FA of the terminal leaf lobe is the most prominent of the criteria used in this study to assess the state of the environment and determine the level of pollution in Novosibirsk.

\section{References}

1. V. M. Pivkin and L. N. Chindyaeva, Ecological infrastructure of a Siberian city (on the example of the Novosibirsk agglomeration), 184 (2002) 
2. V. M. Zakharov, A. T. Chubinishvili, S. G. Dmitriev, and A. S. Baranov, Center for Environmental Policy of Russia, 320 (2000)

3. L. K. Trubina, Stereo models in the study of biological objects, 136 (2006)

4. A. Yu. Lugovskaya, E. P. Khramova, and O. V. Chankina, Rastitel'nyi Mir Aziatskoi Rossii (Plant Life of Asian Russia), 1, 71-77 (2014)

5. Yu. Lugovskaya, E. P. Khramova, and O. V. Chankina, Contemp. Probl. Ecol., 11, 8998 (2018)

6. E. P. Khramova, O. V. Tarasov, and L. K. Trubin, GEO-Siberia-2008. 2, 3-7 (2008)

7. L. K. Trubina, E. P. Khramova, and A. Yu. Lugovskaya, Interexpo GEO-Siberia, 2, 160-163 (2013)

8. J. H. Graham, M. J. Whitesell, M. Fleming II, H. Hel-Or, E. Nevo, and S. Raz, Symmetry. 7 ,255-268 (2015)

9. Franiel, Biodiv. Res. Conserv. 9, 7-10 (2008)

10. D. C. Freeman, J. H. Graham, M. Tracy, John M. Emlen, and C. L. Aladosl. J. Plant Sci. 160, 157-166 (1999)

11. C. P. Klingenberg, S. Duttke, S. Whelan, and M. Kim, Journal of Evolutionary Biology. 25, 115-129 (2012)

12. B. Leung and N. R. Forbes, The American naturalist, 155, 101-115 (2012)

13. G. Q. Lu and L. Bernatchez, Heredity, 742-747 (1999)

14. G. R. Khuzina, Vestn. Univ., 3, 47-52 (2011)

15. M. N. Kuznetsov and L. V. Golyshkin, S.-Kh. Biol. 3, 72-77 (2008) 